\title{
Building an environmentally accountable medical curriculum through international collaboration
}

\author{
Sarah Catherine Walpole, Aditya Vyas, Janie Maxwell, Ben J. Canny, Robert \\ Woollard, Caroline Wellbery, Kathleen E. Leedham-Green, Peter Musaeus, \\ Uzma Tufail-Hanif, Karina Pavão Patrício \& Hanna-Andrea Rother
}

To cite this article: Sarah Catherine Walpole, Aditya Vyas, Janie Maxwell, Ben J. Canny, Robert Woollard, Caroline Wellbery, Kathleen E. Leedham-Green, Peter Musaeus, Uzma Tufail-Hanif, Karina Pavão Patrício \& Hanna-Andrea Rother (2017) Building an environmentally accountable medical curriculum through international collaboration, Medical Teacher, 39:10, 1040-1050, DOI: 10.1080/0142159X.2017.1342031

To link to this article: http://dx.doi.org/10.1080/0142159X.2017.1342031

View supplementary material ¿

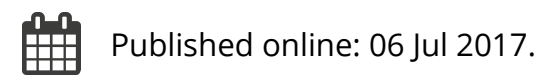

Submit your article to this journal $₫$

III Article views: 167

Q View related articles $₫$

View Crossmark data $\widetilde{ }$ 


\title{
Building an environmentally accountable medical curriculum through international collaboration
}

\author{
Sarah Catherine Walpole ${ }^{\mathrm{a}, \mathrm{b}}$, Aditya Vyas ${ }^{\mathrm{c}}$, Janie Maxwell ${ }^{\mathrm{d}}$, Ben J. Canny ${ }^{\mathrm{e}}$, Robert Woollardf, \\ Caroline Wellbery ${ }^{g}$, Kathleen E. Leedham-Green ${ }^{\text {h}}$, Peter Musaeus', Uzma Tufail-Hanif', Karina Pavão Patríciok \\ and Hanna-Andrea Rother'
}

${ }^{a}$ Hull York Medical School, Hull University, Hull, UK; ${ }^{b}$ Medecins Sans Frontiers, Democratic Republic of Congo; ${ }^{c}$ Norwich Medical School, University of East Anglia, Norwich, UK; ${ }^{d}$ The Nossal Institute for Global Health, The University of Melbourne, Melbourne, VIC, Australia;

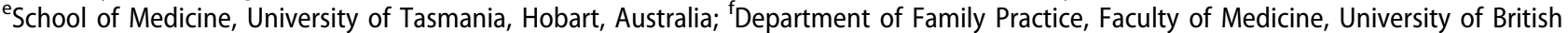
Columbia, Vancouver, BC, Canada; ${ }^{9}$ Department of Family Medicine, Georgetown University Medical Center, Washington, DC, USA; ${ }^{h}$ Department of Primary Care and Public Health Sciences, King's College London, London, UK; 'Centre for Health Sciences Education, Aarhus University, Aarhus, Denmark; ${ }^{j}$ Master of Surgery Degree Programme Co-ordinator, University of Edinburgh, Edinburgh, UK; ${ }^{k}$ Public Health Department, Medical School of Botucatu, Universidade Estadual Paulista, Sao Paulo, Brazil; 'Division of Environmental Health, School of Public Health and Family Medicine, University of Cape Town, Rondebosch, South Africa

\begin{abstract}
Background: Global environmental change is associated with significant health threats. The medical profession can address this challenge through advocacy, health system adaptation and workforce preparedness. Stewardship of health systems with attention to their environmental impacts can contribute to mitigation of and adaptation to negative health impacts of environmental change. Medical schools have an integral role in training doctors who understand the interdependence of ecosystems and human health. Yet integrating environmental perspectives into busy medical curricula is not a simple task.

Content: At the 2016 Association for Medical Education in Europe conference, medical educators, students and clinicians from six continents discussed these challenges in a participatory workshop. Here we reflect on emerging themes from the workshop and how to plan for curricular change. Firstly, we outline recent developments in environmental health and associated medical education. Secondly, we reflect on our process and outcomes during this innovative approach to international collaboration. Thirdly, we present learning objectives which cover core content for environmentally accountable medical curricula, developed through a reflective process of international collaboration integrating current literature and the workshop outcomes.
\end{abstract}

Conclusions: International collaboration can bring together diverse perspectives and provide critical insights for the inclusion of environmental health into basic education for medical practitioners.

\section{Introduction}

Medical schools have a responsibility and an opportunity to prepare tomorrow's doctors to address health issues related to environmental change. The World Health Organization has indicated that one quarter of deaths and global burden of disease are attributable to environmental exposures (Pruss-Ustun and Corvalán 2006). Chemical pollution, including metal and pesticide pollution, is associated with reproductive health problems (Sanborn et al. 2007; Cremonese et al. 2017), cognitive decline (Sanborn et al. 2007), mental health problems (Faria et al. 2014) and cancer (Bassil et al. 2007; Boccolini de et al. 2013). Meanwhile, climate change contributes to evolution of infectious diseases, increased risk from pathogens spread via food and water, food insecurity and malnutrition, natural disasters, migration and conflict and resultant social, economic and health effects (Watts et al. 2015). Thus, anthropogenic environmental change is a significant mental and physical health threat.

Now, more than ever before, the ecosystems that sustain life and human health are threatened (McMichael and Lindgren 2011; Gomez et al. 2013; Watts et al. 2015). "Planetary health" research explores nine planetary systems including climate change, biodiversity, freshwater use and

\section{Practice points}

- Every medical student can benefit from education on environmentally sustainable healthcare, preferably through a spiral curriculum.

- Medical curricula must address principles and practice, preparing students to advocate for and implement change.

- Developing positive attitudes towards environmental sustainability is an essential part of medical professionalism, scholarship, leadership and management.

- International collaboration as an approach to curriculum development builds understanding of new topics and capability to improve education.

biochemical flows. Human activities are destabilizing planetary systems which impact human health through multiple pathways, including food and water insecurity, extreme weather events and socio-political instability (Whitmee et al. 2015). In 2015, the United Nations ratified the Sustainable Development Goals, which provide commitment, stimulus 
and opportunity to "protect the planet from degradation" (UN General Assembly 2015, p. 2) and "improve education, awareness-raising and human and institutional capacity on climate change" (UN General Assembly 2015, p. 14). The inclusion of content on environmentally sustainable healthcare in the medical curriculum is urgently needed.

We define an environmentally sustainable medical curriculum as one that aims to develop medical students' knowledge, skills and attitudes about the interdependence of human health and ecosystems. This includes the effects of environmental change on health, and healthcare's impact and dependence on the local and global environment. Sustainable healthcare education is the organization of medical education (teaching and learning) in pursuit of this aim. In the 1960s, educators from Virginia School of Medicine described a new module for medical students, "Man and his Environment", which covered "Man's physical environment", "Human evolution" and "Human ecology", including health impacts of natural disasters and of industry (Arrington and Hilkovitz 1964). A handful of publications on medical education about ecological or environmental topics followed in the 1970s and 1980s, but it was not until 1990s that publications began to expand insights into the knowledge and learning needs of health professionals in this regard (Takayanagui 1993) and a consensus statement highlighted the importance of medical students addressing environmental threats (Hollan et al. 1998). In 2000s, the concept of ecosystem health was developed, primarily in USA, and its relevance to medical education explored (Rapport et al. 2003; Howard 2004), before "one health", the convergence of environment, animal and human health, began to shape courses in some medical schools (Shomaker et al. 2013). The 2010s have seen sustainable healthcare education being embedded in medical curricula at some schools in the UK (Braithwaite et al. 2012), and publication of consensus learning outcomes (Thompson et al. 2014) case studies and inspiration from other health professionals (Bell et al. 2012; Maxwell and Blashki 2016). Medical curricula that incorporate teaching on environmental sustainability align with social accountability (Boelen 2010), because both movements address how medical schools can work closely with societal institutions to address pressing societal needs. For example, at the intersection of social inequality and climate change we see injustice in the health impacts of environmental change. Thus environmental accountability frameworks (Pearson et al. 2015) under which medical schools actively promote environmental sustainability through education, research and partnerships with communities and health services to address the determinants of health at the local, regional and global levels also address social accountability.

There are compelling reasons for integrating environmental health and sustainability perspectives into medical curricula. Firstly, the long-term viability of healthcare provision is inextricably linked with environmental sustainability (Costello et al. 2009). Health professionals need to be confident in measuring and managing the environmental impact of healthcare, recognizing that supplies of natural resources are finite, and that environmental pollution harms planetary and human health. Secondly, doctors are trusted professionals and have a responsibility to educate and advocate for better environmental health measures to protect public health (RCP 2010). Thirdly, sustainable healthcare education has wide applicability across other areas of the curriculum, for example, through learning about systems thinking, the range of social and environmental externalities that influence health, and the relationship between local and global health (Bell et al. 2012; Maxwell and Blashki 2016).

Although there is a strong rationale for integrating education on environmental sustainability into medical curricula, medical educators may lack the interest or capability to enact the necessary curricular change (Walpole, Pearson et al. 2015). Medical curricula have arguably become static with limited room for change due to regulatory requirements, competing interests, lack of expertise and lack of resources (Gehle et al. 2011; Tomes 2011). While important contributions have been made in developing sustainability curricula for higher education in medicine, as in other disciplines (Filho 2002; Rapport et al. 2003; Blewit and Cullingford 2004; Gehle et al. 2011), there is a lack of international engagement on the specific design of an environmentally accountable medical curriculum.

To address these complex issues and the current gap in medical curricula, we facilitated an international collaboration to share experiences and ideas about including environmental sustainability in mainstream medical education (that is, the curricular content that all medical schools should include). In this paper, we provide reflection on our process and a practical guide for integrating environmental sustainability into existing medical curricula, recognizing that institutional, curricular and cultural contexts will affect implementation.

We reflect on the design, development and implementation of an innovative platform for international collaboration at the Association for Medical Education in Europe (AMEE) 2016 conference, describe results of workshop discussions, and outline our reflection and recommendations about learning objectives for environmentally accountable medical curricula. This paper builds on existing literature (Rapport et al. 2003; Wilcox 2004; Green et al. 2009; Bell 2010; Bell et al. 2012; Walpole, Pearson et al. 2015; Maxwell and Blashki 2016) and the experiences of the sustainable healthcare education network which is a collaboration of health educators, students and health service leaders in the United Kingdom (UK). In particular, we explore the extent to which previously established environmentally and socially accountable learning objectives (Walpole, Mortimer et al. 2015) are relevant and can be incorporated into future medical education initiatives internationally.

\section{Methods}

Curriculum development and reform in medical education at its best is an iterative process that draws on evaluation of current teaching, engages students and other stakeholders, and recognizes emerging health and healthcare priorities (Fetterman et al. 2010). We used Kern's 6-step approach to curricular development as guidance, with problem identification, general and specific learner-focused needs and learning objectives as our initial focus (Kern et al. 1998). At the same time, we incorporated Fink et al.'s "backward design" approach to curriculum design proposed by relating learning outcomes to teaching activities and assessment (Fink 2003). Although learning objectives are the primary output of this paper, we draw on Fink's 
approach to curriculum development, which addresses the need to integrate and apply learning and to engage students' caring by addressing the human dimension to this learning. Because the concepts of planetary health and environmental sustainability challenge many societal and health professional norms and expectations, and evoke wide-ranging responses influenced by individual and societal attitudes and values (Coelho et al. 2006; Rawlins et al. 2007; Keskin et al. 2011), we needed a dynamic consensusbuilding approach that acknowledged existing curriculum development frameworks (Kern et al. 1998; Fink 2003).

We brought together diverse perspectives using a constructivist approach, where individuals' experiences and perspectives of sustainability were brought together and sometimes challenged by other individual or inter-individual ideas; leading to debate, discussion and finally a set of collaboratively constructed and agreed objectives (Gash 2009). Drawing on Donald Schön's (1987) notion of "reflective practice", we actively reflected on our collective actions as we undertook the design and execution of the process. Schön (1987) argued that reflective practitioners are continually aware of and explore the process (reflection in action) and outcomes (reflection on action) of their actions. Reflective practice enables practitioners to critically examine practice such that they are constantly learning and their practice is continually evolving in response to new learning. While a structured process such as a Delphi is valuable to develop consensus from experts at a given point in time (Jones and Hunter 1995), we sought to engage in a process that would be iterative in nature, value diverse contributions and pave a way for ongoing collaboration to support curriculum development and delivery. We thus developed a dialogic approach based on the principles outlined by Schön. Reflective practice was particularly valuable during this project, because both the methods of collaboration and the task of developing a framework for an environmentally accountable curriculum that can be adapted for international use are relatively novel.

We facilitated collaborative engagement during a participatory workshop in August 2016 at the AMEE annual conference in Barcelona, Spain. The methods consist of three parts: (1) pre-workshop engagement and preparation, (2) the workshop itself, and (3) analysis of workshop findings and development of learning objectives based on workshop outcomes. Our e-collaborative process allowed for relatively "flat" (non-hierarchical) engagement as well as international engagement without a "host nation". The two factors which enabled our success in this endeavor were our desire to collaborate and share learning rather than compete to produce knowledge, and our varied and complementary expertise and skills.

Based on our knowledge of the literature and challenges at our own institutions, we set the following aims for this project. To:

1. Foster innovation for addressing environmental issues related to health in mainstream medical education.

2. Identify how to incorporate sustainable healthcare education at medical schools, including through educatorstudent partnership.

3. Undertake collaborative curriculum development with participants from around the world, using technology to facilitate the involvement of remote participants.
4. Demonstrate a collaborative approach to developing environmentally sustainable medical curricula.

The process that we employed for developing sustainable healthcare learning objectives is illustrated in Figure 1.

\section{Pre-workshop}

We anticipated that learning to develop environmentally sustainable medical curricula could be enhanced by sharing international perspectives. Four authors (SCW, HAR, BJC and $\mathrm{AV}$ ) and Eleanor Dow (a UK medical student) collaborated to develop the above four aims and identified the AMEE conference 2016 as an ideal opportunity to address them. Ideas for session activities were suggested by the authors based on important leverage points and gaps in the evidence base that had been identified in previous workshop experiences, case studies and discussion about progress and challenges in medical schools in different continents and previous collaborations for education development. Online collaboration platforms used were Google Docs and Skype videoconferencing. Informed by the existing literature (Walpole, Mortimer et al., 2015; see also Table 1 column 1), five workshop themes were devised as a basis for discussion of the aspects of environmental sustainability relevant to medical education (Figure 1). The five themes were:

1. The health impacts of environmental change

2. Sustainable and healthy lifestyles (focus on individual behaviors)

3. Sustainable and healthy societies and communities (focus on population level interventions)

4. The environmental footprint of health services

5. The ethics of sustainability.

For each of the five themes an online Google document providing a summary of the topic and key questions for education development was created by the workshop authors (SCW, HAR, BJC, AV) and Eleanor Dow. Presentations were prepared to highlight important issues for educators developing and implementing new curricular material (Figure 1).

In order to broaden participation, the authors disseminated an invitation through the Sustainable Healthcare Education network, an online open-access network of students and educators based in the UK but with international members. This invitation outlined session aims, structure and logistics. The workshop was also advertised in the AMEE conference program. Those not attending AMEE were able to participate remotely through Skype. An online survey on SurveyMonkey allowed participants to sign up for remote participation ("Survey for Sign up to Workshop" 2016).

\section{Workshop}

During the workshop, we sought to facilitate active participation to develop a framework for sustainable healthcare education, and to reflect on the lessons learned from this process, assuming the stance of reflective practitioners (Figure 1). A priority was to engage participants in a cooperative process of listening and reflecting on their 


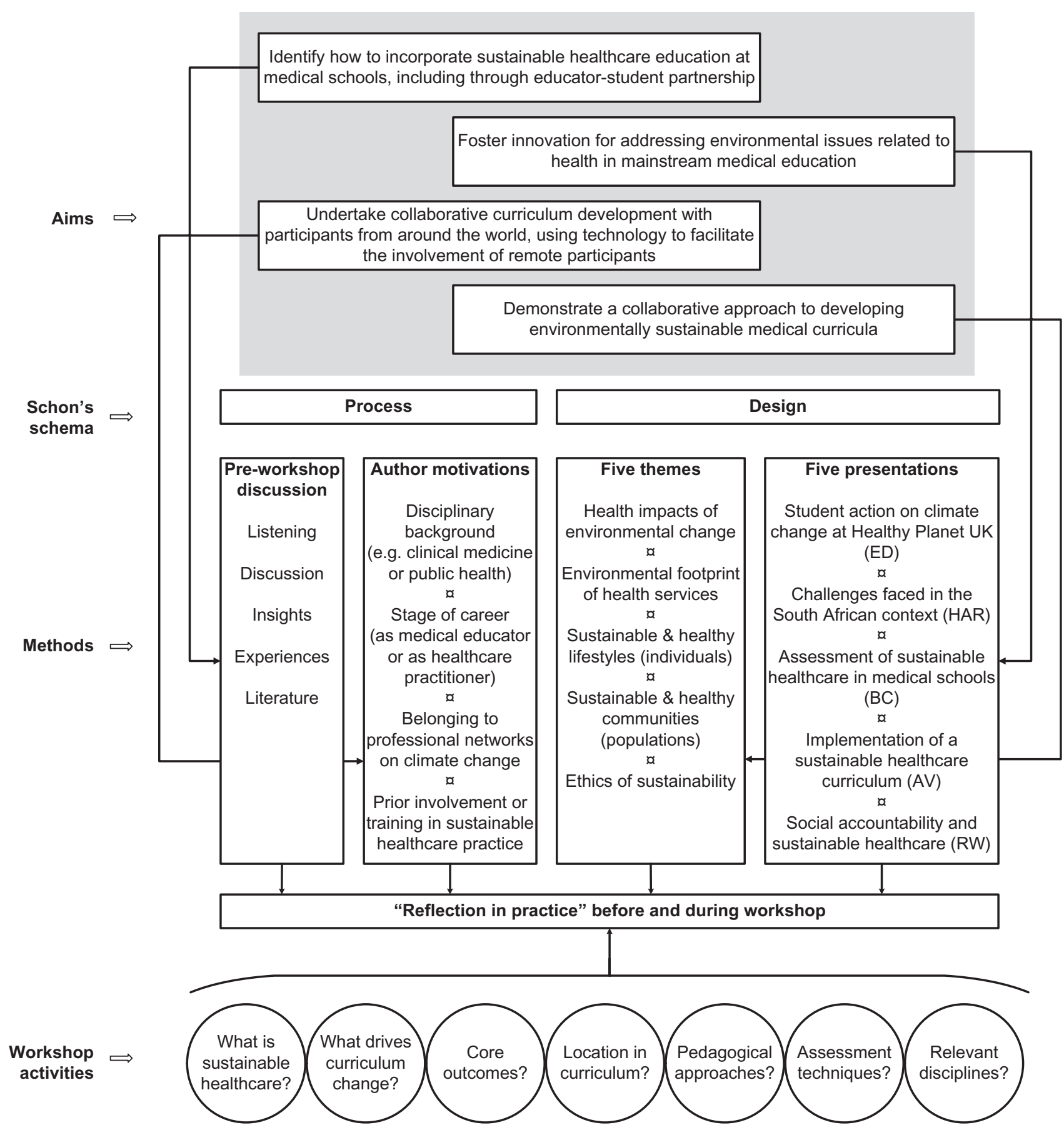

Figure 1. Outline of methods used in this collaboration, following the Schön (1987) schema of reflective practice.

own, other participants' and organizers' input, to give new meanings and directions to the collaborative project and design of the framework.

As the AMEE conference is organized by and for health professional educators and students, other experts and members of the public were not included in the discussion. Skype participation was available to any individual who signed up, but was only advertised through health professional educator networks.

To prompt reflection, at the commencement of the workshop, participants were invited to independently define sustainable healthcare and consider drivers of curriculum change. Introductory presentations provided key concepts and definitions, such as planetary health; educational approaches, for example for teaching environmental history taking and assessment for sustainable healthcare education; and case illustrations from South Africa and the UK (Figure 1).

Participants at AMEE self-selected into one of five groups, which each addressed one of the five themes. The online group elected to work on the 'environmental footprint of healthcare services'. The groups worked for $35 \mathrm{~min}$ to address the questions on the Google Doc for their theme (see supplementary appendix). Facilitators took notes on paper and typed onto the Google Doc to record the discussion, and each group presented a summary to all workshop participants.

\section{Post-workshop}

All contributions recorded on paper during the workshop were transcribed onto the relevant document on Google 
Docs (by SCW) and all authors undertook post-workshop reflective discussions and content analysis. Building from the Google Document which each group populated during the workshop with the outputs of their discussion (see appendix), we used a constructivist approach and referred to Bloom's taxonomy (Eisner 2000) and the medical education literature to create a coherent set of learning objectives spanning five core domains of sustainability that were discussed in the workshop. The content of the learning objectives derived from the workshop, and the medical education literature provided the taxonomy to create clear, achievable and demonstrable learning objectives. Based on workshop contributions, the authors felt that categories two and three overlapped significantly such that they should be combined. After the authors completed a full draft set of learning objectives, the set of learning objectives was shared with all workshop participants who had provided their email address for further edits or validation. No further edits were suggested by participants.

\section{Results}

\section{Participants}

Approximately 35 participants (including six presenters and organizers) attended the workshop in person with an additional five attending via Skype videoconferencing. All participants were health professionals; five were students and the remainder were educators or clinicians with a range of prior experience of sustainable healthcare education, from none to leading sustainability modules. Face-to-face participants included pharmacist educators, medical school faculty, clinical educators, and medical students from high, middle and low income countries (e.g. Australia, Brazil, Canada, Denmark, South Africa, Thailand). Skype participants were a nurse educator, a medical educator and two medical students from the UK; a family physician from Australia; and a medical teacher from Brazil. The strength of the group of participants lay in the diversity of experiences and perspectives of medical education that it collectively held, rather than in in-depth expertise about the topic of focus, environmental sustainability.

\section{Definition of sustainable healthcare}

Workshop participants' ideas about the definition of sustainable healthcare were consistent with accepted definitions of sustainability (Brundtland Commission 1987) and sustainable healthcare (Pearson et al. 2015). Participants emphasized healthcare delivery that takes into account impacts on planetary health and the needs of future generations. They emphasized the need for healthcare that addresses social and environmental determinants of health; promotes healthier and sustainable lifestyles; manages resources efficiently; minimizes waste; reduces financial and carbon costs; is socially responsible, ethical and equitable; is climate-resilient; and adapts to changing requirements of the population served.

\section{Content of sustainable healthcare education}

Each group developed learning objectives for their particular theme, which are presented in Table 1 column 2 . The revised set of learning objectives developed after the workshop are presented in Table 1 column 3. This post-workshop phase was undertaken over a three-month period by the eleven authors, through an iterative, reflective process of online discussion, knowledge sharing, and building a collective understanding, facilitated by a shared online Google Doc kept up to date by the coordinating author (SCW).

\section{Strategies for creating environmentally sustainable medical curricula}

Recommendations for timing, pedagogies and assessment for sustainable healthcare education were predominantly developed during the workshop, without further adaptation during the post-workshop phase of the project.

\section{A. Where in the curriculum could environmental content} be taught?. In every theme, participants suggested that the learning objectives could be addressed in a spiral curriculum, that is an integrated multi-year curriculum where content introduced in the first year is built upon in subsequent years. It was suggested that environmental sustainability should be a cross-cutting theme, similar to communication skills or professionalism, incorporated into all relevant aspects of classroom-based and clinical education.

Participants said that each theme should be represented across the curriculum, through integration into existing educational sessions. Conversely, any newly developed sessions could link to existing topics in the medical curriculum. Participants identified topics in their established medical curricula (including, but not limited to epidemiology; occupational health; public health; respiratory disease; dermatology; global health; and toxicology) that readily link to environmental sustainability.

B. How could environmental content be taught? Through group discussion, it became apparent that a broad range of pedagogical approaches could support learning about the impacts of the environment on health. Didactic teaching (e.g. through an initial lecture or e-learning) can be offered to establish importance and describe fundamental principles of sustainable healthcare, as well as to establish a common body of knowledge amongst students. Additionally, a case-based approach (either student-led or tutor-led) could be most appropriate to help students engage with topics in more depth, and establish the relevance to their future practice. Eco-medical literacy can be developed through routine inclusion in case-based learning, where environmental risk factors are considered alongside social determinants of health and biomedical risk factors in each pre-clinical patient case study. Meanwhile, community case studies or specific patients with an environmentrelated illness could prompt opportunistic learning to promote eco-medical literacy.

Workshop participants agreed that teaching content that relates to reducing the environmental footprint of healthcare could be introduced through practical and skills-based approaches. This might include individual or group project work, such as student electives, student-selected modules, audits, community interventions, and quality improvement projects. Associated skills could be introduced through core workshops with simulation opportunities, and formative 
Table 1. Key learning objectives for an environmentally accountable curriculum.

Pre-workshop consensus learning objectives identified in the literature Source: Walpole, Mortimer et al. (2015)

Describe how the environment and human health interact at different levels

Demonstrate the knowledge and skills needed to improve the environmental sustainability of health systems
Workshop learning objectives developed by workshop participants

Health impacts of environmental change

- Awareness of environmental exposures and health threat impacts and opportunities arising from local and global environmental change

- Understand how environmental health issues relate to mainstream medical disciplines such as epidemiology, public health, respiratory health, toxicology

- Be able to conduct environmental health history as a routine part of patient history taking

- Understand current issues and projected changes in environmental health

- Demonstrate knowledge of prevention strategies for environmental health problems

Sustainable and healthy lifestyles

- Understand how individual lifestyle choices promote an individual's well-being, while simultaneously promoting a healthy local and global environment/ecosystem ("health co-benefits")

- Describe environmentally healthy lifestyle choices that individuals can make in the short- and longterm

- Demonstrate health promotion communication skills which encourage patients to contemplate and maintain healthier and more sustainable behaviors

Sustainable and healthy societies and communities

- Understand how health policies have both a positive and negative impact on environmentally sustainable healthcare

- Provide examples of health policies affecting sustainable healthcare, and critically analyze their impact at the global, national and local (community) levels

- Understand how policies can affect sustainability and environmental health

- Develop a vision for sustainable and healthy communities, and formulate a healthcare practitioner's role within such a society

- Describe the role of healthcare professionals in leading, expressing and influencing the behaviors and policies that promote a sustainable and health society

The environmental footprint of health services

- Understand the sustainability impact of clinical practice and identify sources of unsustainability in healthcare

- Demonstrate systems thinking

- Demonstrate knowledge of different healthcare systems e.g. Cuban health services

- Explore definitions of healthcare value - appreciating that it is ultimately complex, where there are costs in achieving one bottom line

- Undertake a quality improvement project to identify and address an area where sustainability could be improved

- Demonstrate knowledge of individual role in contributing to sustainable healthcare systems and ecological footprint reduction mechanisms
Post-workshop learning objectives post-workshop analysis

Source: integrated findings from the literature and the workshop

Develop eco-medical literacy \& clinical preparedness

- Describe the mechanisms by which human health is affected by environmental change (for example through changes in disease vectors, exposure to extreme weather, migration and reduced food security).

- Describe the impacts of global and local environmental change as they relate to specific medical disciplines (including but not limited to cardiology, respiratory medicine, psychiatry, toxicology and epidemiology).

- Identify the environmental determinants of health in a range of geographic, socioeconomic and cultural contexts

- Demonstrate the ability to take an environmental health history within a patient consultation

- Design individual and population-focused strategies for doctors to reduce the health impact of environmental change (in both clinical practice and public health advocacy)

Promote patient eco-health literacy

- Explain the concept of "health co-benefits" by considering how lifestyle choices can simultaneously promote both patient wellbeing and a healthy local and global environment.

- Define the different dimensions of action (e.g. short- versus long-term; individual- versus community-based; clinical versus structural solutions) which can guide patients towards environmentally sustainable lifestyle choices.

- Demonstrate health promotion communication skills which encourage patients to contemplate and maintain healthier and more sustainable behaviors.

Promote community eco-health literacy

- Demonstrate the process of conducting a health impact assessment that accounts for environmental factors

- Explain the concept of "health in all policies", giving examples of how policy can affect the social and environmental determinants of health, as well as healthcare delivery

- Identify the role of healthcare professionals in advocating for policies and infrastructure that promote availability, accessibility and uptake of healthy and sustainable behaviors

Deliver sustainable health systems

- Evaluate the environmental, economic, social and health costs and benefits of different models of healthcare delivery (including but not limited to resource distribution between prevention and treatment, and between primary and secondary/ tertiary care)

- Identify different ways in which doctors can contribute to the delivery of sustainable healthcare systems (including clinical and leadership roles)

- Participate in quality improvement processes that aim to measure and improve the sustainability of a healthcare service, considering not only the intended health benefits, but the associated financial, social and environmental costs

- Apply systems thinking and multidisciplinary per spectives to patient care and resource management, in order to promote the sustainability of health services 
Pre-workshop consensus learning objectives identified in the literature Source: Walpole, Mortimer et al. (2015)

Discuss how the duty of a doctor to protect and promote health is shaped by the dependence of human health on the local and global environment
Workshop learning objectives developed by workshop participants

Ethics of sustainability

- Build on basic principles of environmental ethics

- Understand individual environmental footprint and how to reduce

- Advocate for environmental justice and health

- Critically appraise concepts of healthcare value, including the principles that underpin definitions of health outcomes and costs
Post-workshop learning objectives post-workshop analysis

Source: integrated findings from the literature and the workshop

Practice responsible professionalism

- Apply the concept of "environmental justice" to explore the impacts of environmental policies on health and health inequalities

- Discuss how doctors can overcome the ethical tension of meeting individual patient needs versus the responsibility to champion a healthy environment (e.g. adopt a utilitarian perspective, or consider the four principles of biomedical ethics)

- Explain how the interdependence of humans and ecosystems affects medical professionalism and the responsibilities of doctors and medical students (e.g. consider the need for sustainable clinical practice, health system leadership, social accountability and health advocacy)

Recognize and articulate personal values concerning environmental sustainability, by considering the relationship between the environment and the health and the impact of environmental change on current and future generations assessments, such as portfolio entries and objective structured clinical examinations (OSCEs). Examples of these core skills include behavior change techniques to foster healthy behaviors; supporting self-care and active patient-participation in disease management; procurement of sustainable materials; and efficient use of resources to reduce waste from healthcare, including medications waste.

There is an ethical element to environmental sustainability associated with social justice, universalism and benevolence. This cannot be prescribed or learnt didactically but can be actively debated and role modeled by peers, health professionals and teachers. Existing biomedical ethics teaching, whether stand-alone or integrated as part of a spiral curriculum, could be modified to promote this debate, with attention paid to the culture of an organization so that these values can flourish. As environmental impacts closely reflect global inequities, students can learn about environmental social justice, which is especially important for countries with the populations most at risk of the negative health effects of climate change and environmental degradation. Ethical discussions about environmental responsibility could be linked to any existing or newly introduced global health content.

Other ideas for suitable pedagogies included debates about solutions to environmental problems, group work adopting different stakeholder perspectives, self-directed research projects and reflective exercises.

\section{What assessments are appropriate for environmental} content?. Workshop participants identified that assessments must be closely linked to the objectives and pedagogies chosen. Following the conceptual framework outlined by Cox (2005), students could be asked to demonstrate a positive change they have made, through a reflective portfolio or case-based discussion; to submit a project report such as an audit or quality improvement project; or to demonstrate their understanding of core concepts through written tests. Assessments that promote deep engagement and breadth of learning across values, skills and knowledge could be prioritized. Due to the complex and evolving nature of this broad area of study, assessment modalities should not be confined to simple factual recall. For example, deeper learning can be achieved through project work, essays and reflective writing, debates and presentations, rather than less nuanced modalities such as multiple choice questions. The assessments could require students to explore their own values and reflections on transitioning from observers to active participants and leaders in the implementation of environmentally sustainable healthcare. Another practical means to assess competence related to sustainable healthcare is through service learning or problematization (Prado et al. 2012), where a group of students studies a topic, engages with community and social facilities, and co-develops interventions to improve health impacts of environmental issues facing the community.

\section{Conditions for curriculum implementation}

Workshop participants described internal and external factors that are needed to support curricular innovation in medical schools. The absence of these factors could constitute barriers to successful implementation. Internal facilitating factors included leadership at many levels of the medical school from the Dean's office to students; support of key members of faculty; student-driven demands; and research interests related to environmental topics at the institution. External factors included guidance from professional organizations, political pressure, legislative change, societal or patient group expectations, technological innovation to facilitate sustainable healthcare, and an increasingly nuanced understanding of quality in healthcare and threats to health. Discussions post-workshop concluded that identifying a local champion and providing the necessary leadership skills and support was key to implementing curriculum change.

\section{Post-workshop learning areas and objectives}

Building on the workshop findings, scholarly literature and follow-up collaborative discourse, the authors categorized the learning objectives under five domains to make up a whole environmentally accountable medical curriculum. 
These domains are listed below and form the structure for the third column in table one.

- Develop eco-medical literacy and clinical preparedness

- Promote patient eco-health literacy

- Promote community eco-health literacy

- Deliver sustainable health systems

- Practice 'responsible professionalism' (Rapport et al. 2003)

\section{Discussion}

This project has developed a model for collaborative curriculum development that offers potential strategies for consolidating sustainable healthcare education, and could be applied to other educational topics.

\section{Sustainable healthcare knowledge}

Participants demonstrated wide ranging but congruent understanding of the meaning of sustainable healthcare. As participants self-selected to attend the workshop, they are likely to have greater motivation and/or literacy in this domain compared to the broader AMEE cohort and other medical students and educators. Recent surveys of doctors and medical students in Cuba (Cabrera and Tomey 2010), healthcare workers in China (Su et al. 2011) and public health doctors in the UK (Charlesworth et al. 2012) all indicated that health students and professionals have some awareness of sustainability but lack knowledge of many aspects. Surveying a more representative group of students and educators about sustainable healthcare education would garner useful information on current levels of awareness. This could be done at a future AMEE conference through the recently introduced "Wisdom of our crowd" approach (AMEE 2015) in which all present at a lecture respond to questions via an online poll.

\section{Priority of sustainable healthcare education}

Despite the magnitude and variety of the challenges posed by environmental change, the topic has been given relatively little attention in medical education. For example, there has been only one session about environmental issues at the last three AMEE annual conferences. The low status of environmental sustainability at the AMEE conference reflects the broader lack of environmentally accountable medical education globally (Gehle et al. 2011). A systematic review identified only one paper providing a framework for medical education on this topic (Walpole, Pearson et al. 2015), and we have identified only one further framework published since, proposing learning objectives related to climate change (Maxwell and Blashki 2016).

\section{Reflective curriculum development}

A thread in the post-workshop discussion was that, as educators wanting to teach internationally relevant curriculum on sustainable healthcare, we might become caught in what Schön (1987) called the "squeeze play" where rising technical rationality (manifesting as medical sub-specialization) and technical power (giving weight to the measurable and generalizable) crush any ambition to teach medical students the generalist, integrative, holistic, and relationship-based artistry of clinical practice. The implications we draw from the workshop discussion, viewed through Schön's theoretical lens, is that the aim should not be to make the physician a technician-expert on sustainability. Rather, the goal could be to balance the various tensions between professional standards versus professional freedom and between biomedical needs and interventions versus social needs and interventions. This means that in order to inspire future physicians to develop appropriate attitudes and wisdom, as well as knowledge and skills, we need to design a spiral-curriculum where medical students encounter topics about environmental sustainability throughout medical school and with increasing complexity and a systematic approach to building on previous learning.

The workshop discussion focused on practical implementation and assessment strategies is an important first step. However, medical education not only needs to equip medical students with knowledge about environmental sustainability, but also familiarity with their own attitudes and capacity to contribute to advocacy and leadership in environmental health. Medical education needs to address the knowledge, attitudes, and skills necessary to tackle complicated issues including environmental medicine, ethics and communication. In this paper we have addressed our concern that at present it is up to the individual educator to incorporate topics on environmentally sustainability into his or her courses. As an alternative, we present the first attempt at agreement on what a spiral curriculum addressing the development of environmentally sustainable healthcare and an environmentally accountable curriculum might look like (Table 1 column 3).

Specifically, through this collaborative project, we identified five overarching domains in which students can meet learning objectives within their spiral program (Table 1 column 3). For achieving competency in an environmentally accountable curriculum, students need to have developed proficiency in eco-medical literacy (see glossary) and clinical preparedness that shows an understanding of environmental health concepts and research. Furthermore, medical students will be required to reflect this solid grounding in sustainable healthcare education through promoting ecohealth literacy among their patients encouraging preventive and healthy lifestyles. This grounding could further be reflected in medical students' ability to promote community eco-health literacy (see glossary) which is aimed at improving the policies and health systems to foster preventive and healthy lifestyles at the community level. Medical curricula need to provide the tools for medical students to ensure delivery of sustainable systems and their role in this process. Finally, the fifth overarching learning objective is that medical students need training that supports them in practicing responsible professionalism specifically in relation to environmental sustainability.

In the spirit of this international undertaking, which is rooted in collaborative reflective practice, we present this as an ongoing open discussion rather than as a fixed monologue and inflexible framework. We have demonstrated that, with effort and time, it is feasible to engage a broad range of participants from across the global commons in this work. Technology supported engagement 
allowed this globally distributed group to participate in reflective dialog and collaborative engagement in real time. Through this process we have synthesized a collective knowledge. In doing so, we meet the challenges posed by sustainability, whose pervasiveness and complexity requires global dialog and intersectoral collaboration. Just as social accountability incorporates partnership with extra-academic stakeholders in medical education, development of environmentally accountable curricula can effectively be achieved within the "partnership pentagram" model, which involves communities, policy makers, health administrators, health professionals and academics (Boelen 2000). We hope that lessons from the methodological approach used in this project can be applied at a wider operational level to include these extra-academic partners.

\section{Limitations to this approach to educational development}

This project has three main limitations. Firstly, participants were self-selecting and are unlikely to be representative of the global cohort of medical educators in terms of cultural, ethnic, social, economic or political background. Due to the location and cost of the AMEE conference, participation was weighted towards Europeans and representatives from higher-income countries. Although free online participation was made available, distribution of the invitation to the workshop was primarily through a UK-based network. Secondly, workshop time constraints limited opportunities for engagement both within and between groups. As there was no time for discussion between groups, the findings of each group were not able to be systematically formatted, challenged or validated by all 35 participants. This contributed to a lack of coherence between findings from different groups and validation of the written reports. This was addressed to some extent in the post-workshop analysis process where a member of each of the six groups contributed to developing the final set of learning objectives. Thirdly, there was a risk of information bias as the five domains and associated presentations were prepared in advance in order to facilitate consensus development among participants. Despite scholarly support for the selection of these themes, there was probably not adequate flexibility to reevaluate these during the workshop.

\section{Collaborative environmental curricula}

Our study has shown that, although the practicalities of curriculum implementation are dependent on the local context, there are common opportunities and challenges for implementation, and a common set of pedagogies and principles that warrant the creation of guidelines based on international agreement. Furthermore, the collaborative design of this project, by its very nature, takes into account a broad range of national and institutional contexts and represents a positive approach to designing an internationally applicable set of curricular recommendations. Our approach uses a platform that reduces the barriers to participation that are faced particularly by low and middle income countries with scarce financial and faculty resources.

Introducing new curriculum topics and approaches in medical courses can be difficult to achieve, in part due to a lack of acceptance from medical school faculty. This challenge, which may be simple inertia or a fear of being an "early adopter", could be addressed by outlining a set of sustainable healthcare learning objectives and presenting them for national accreditation by medical education boards.

Participants aired the view that respectful acknowledgement of specific contexts, together with a commitment to mutually support positive change, would be the most reasonable approach to embedding these topics into medical school curricula, thereby maximizing global impact. Our expertise was complementary rather than competing allowing us to build on each other's work rather than create factions. The universal values that drove us to engage with this topic are diametrically opposed to the values that drive personal empire building and therefore a more fluid approach was feasible, with all contributors being listened to. The fact that none of us work or study at the same institution or have competing research interests created an exceptionally 'safe' workspace for a thoughtful and respectful collaborative process.

\section{Conclusions}

Today's medical students need to be better prepared to address the health challenges posed by a changing global environment. Students need a curriculum that enables a more proactive and better informed preventive role for future doctors as agents for change. We recommend that further research explores how these international learning objectives can be adapted to varied national and local contexts, what faculty development requirements accompany introduction of an eco-health curriculum and how these requirements can be met. Further curriculum development should explore how to engage educators in the process, and the most effective educational strategies and curricular implementation approaches as outlined by Kern in his sixstep approach.

Establishing learning objectives through engaged collaboration is a key step in developing a dialog on sustainable healthcare education. Based on our experience and findings in this project, we advocate for a collaborative approach, involving all stakeholders through both face-toface and online participation. Dialogue about a theoretically-informed collaborative process might allow for the practical application of concepts of environmental sustainability into medical curricula, such that students will be able to learn, with immediacy, the relevance of the environment to their responsibilities in delivering healthcare to individuals and communities. A further benefit is providing a platform for developing progressive curricula that schools scarce financial and faculty resources can use to optimize resources and modify for local context. Medical schools, educators and students not only have a responsibility, but also an opportunity to promote a sustainable medical curriculum for the betterment of our global and local environment, with resulting benefits to individual and global health.

\section{Acknowledgements}

The authors would like to thank the following for their valuable contributions to this paper's findings: David Pearson, Eleanor Dow, Heather 
Baid, Andrew Punton and non-author participants in the AMEE 2016 workshop.

\section{Disclosure statement}

AV and SW are members of the Sustainable Healthcare Education network core working group, but have no financial or other non-financial conflict of interest. All other authors declare no conflict of interest and ICJME forms are available on request from the corresponding author.

\section{Glossary}

Eco-health: The field of study which examines the impact of changes in biological, physical, social and economic environments on human health. Through a transdisciplinary approach, eco-health aims to study and understand how ecosystem changes impact human health and propose solutions to reduce or reverse the negative health effects of such changes (Wilcox 2004).

Eco-health literacy: A patient's ability to gain access to, understand and use environmental health information to improve their health (adapted from Bell 2010).

Eco-medical literacy: A doctor's ability to gain access to, understand, and use information to improve environmental health and sustainable healthcare (adapted from Bell 2010).

Sustainable healthcare education: "Teaching and learning which prepares future health professionals to promote sustainable health and deliver sustainable healthcare" (Walpole and Mortimer 2017).

Walpole SC, Mortimer F. Forthcoming 2017. Evaluation of a collaborative project to develop sustainable healthcare education in eight UK medical schools. Public Health. doi: 10.1016/ j.puhe.2017.05.014

\section{Notes on contributors}

Sarah Catherine Walpole, BSc, MBChB, MRCP, MSc (Res), is an Honorary Lecturer, Hull York Medical School, UK and currently working as edical doctor for Medecins sans Frontiers, in the Democratic Republic of Congo.

Aditya Vyas, MBBS, MPH, is a Lecturer in Public Health, Norwich Medical School, University of East Anglia, UK

Janie Maxwell, MBBS, BMedSci, DRANZCOG, FRACGP, is a General Practitioner, Associate Lecturer, The Nossal Institute for Global Health, The University of Melbourne, Australia

Ben J. Canny, BMedSc, MBBS, PhD, is Head of School, School of Medicine, University of Tasmania, Australia

Robert Woollard, MD, CCFP, FCFP, LM, is a Professor, Department of Family Practice, Faculty of Medicine, University of British Columbia, Canada

Caroline Wellbery, MD, PhD, is a Professor, Department of Family Medicine, Georgetown University Medical Center, USA

Kathleen E Leedham-Green, MBBS, BSC, PG Cert APHE, C DipMed Ed, AF HEA, is a Teaching Fellow, Department of Primary Care \& Public Health Sciences, King's College London, UK

Peter Musaeus, MSc, PhD, is an Associate Professor, Center for Health Sciences Education, Aarhus University, Denmark

Uzma Tufail-Hanif, MRes, PhD, is Master of Surgery degree Programme Co-ordinator, University of Edinburgh, UK

Karina Pavão Patrício, MD, PhD, is a Professor, Public Health Department, Medical School of Botucatu, Universidade Estadual Paulista (UNESP), Brazil

Hanna-Andrea Rother, BA, MA, PhD, is an Associate Professor and Head of Environmental Health Division, School of Public Health and Family Medicine, University of Cape Town, South Africa

\section{References}

AMEE. 2015. Wisdom of Our Crowd Session Description. Conference Programme 2015. https://amee.org/getattachment/Conferences/ AMEE-Past-Conferences/AMEE-2015/Section-2-Final-Post-ConferenceUpdate.pdf.

Arrington GE Jr, Hilkovitz G. 1964. Man and his environment: a new course of study at the Medical College of Virginia. J Med Educ. 39:704-711. http://ovidsp.ovid.com/ovidweb.cgi?T=JS\&PAGE=reference $\& D=$ med $1 \& N E W S=N \& A N=14157068$.

Bassil KL, Vakil C, Sanborn M, Cole DC, Kaur JS, Kerr KJ, Sanin LH. 2007. Cancer health effects of pesticides. Can Family Phys. 53:1704-1711.

Bell EJ. 2010. Climate change: what competencies and which medical education and training approaches? BMC Med Educ. 10:31.

Bell EJ, Horton G, Blashki G, Seidel BM. 2012. Climate change: could it help develop 'adaptive expertise'?. Adv in Health Sci Educ. 17:211-224.

Blewit J, Cullingford C. 2004. The sustainability curriculum - the challenge for higher education. London: Earthscan/Routledge.

Boccolini de PMM, Boccolini CS, Chrisman J. d R, Markowitz SB, Koifman S, Koifman RJ, Meyer A. 2013. Pesticide use and nonHodgkin's lymphoma mortality in Brazil. Int J Hygiene Environ Health. 216:461-466.

Boelen C. 2000. Towards unity for health: challenges and opportunities for partnership in health development. Geneva: World Health Organization. http://www.who.int/hrh/documents/en/TUFH_challenges. pdf.

Boelen C. 2010. Global Consensus on Social Accountability of Medical Schools. Vol. 23. Vandoeuvre-Lès-Nancy: Santé Publique. [accessed 2017 Mar 23]. http://www.ncbi.nlm.nih.gov/pubmed/21896218.

Braithwaite I, Mortimer F, Thompson T, Walpole SC, Barna S, Gillam S, Broad J, Maudsley G, Hastings A. 2012. Case studies: UK medical school teaching on sustainability, climate and health. Oxford: Centre for Sustainable Healthcare. [accessed 2017 Mar 23]. http://sustainablehealthcare.org.uk/sustainable-healthcare-education/resources/ 2013/05/case-studies-teaching-climate-sustainable-healthc.

Brundtland Commission. 1987. Report of the world commission on environment and development: our common future. United Nations.

Cabrera IR, Tomey AV. 2010. Nivel de Conocimientos de La Dimensión Ambiental En La Carrera de Medicina. Educ Med Super. 24:445-453.

Charlesworth KE, Ray S, Head F, Pencheon D. 2012. Developing an environmentally sustainable NHS: outcomes of implementing an educational intervention on sustainable health care with UK public health registrars. NSW Public Health Bull. 23:27-30.

Coelho JAP, Gouveia VV, Milfont TL. 2006. Valores Humanos Como Explicadores de Atitudes Ambientais E Intenção de Comportamento Pró-Ambiental. Psicol Estud. 11:199-207.

Costello A, Abbas M, Allen A, Ball S, Bell S, Bellamy R, Friel S, Groce N, Johnson A, Kett $M$, et al. 2009. Managing the health effects of climate change: lancet and University College London Institute for Global Health Commission. Lancet. 373:1693-1733.

Cremonese C, Piccoli C, Pasqualotto F, Clapauch R, Koifman RJ, Koifman S, Freire C. 2017. Occupational exposure to pesticides, reproductive hormone levels and sperm quality in Young Brazilian Men. Reproduct Toxicol. 67:174-185.

Cox E. 2005. Adult learners learning from experience: using a reflective practice model to support work-based learning. Reflective Practice. 6:459-472.

Eisner EW. 2000. Benjamin bloom. Prospects. 30:387-395.

Epstein RM. 2007. Assessment in medical education. N Engl J Med. 356:387-396.

Faria NMX, Fassa AG, Meucci RD, Fiori NS, Miranda VI. 2014. Occupational exposure to pesticides, nicotine and minor psychiatric disorders among tobacco farmers in Southern Brazil. NeuroToxicology. 45:347-354.

Fetterman DM, Deitz J, Gesundheit N. 2010. Empowerment evaluation: a collaborative approach to evaluating and transforming a medical school curriculum Acad Med. 85:813-820.

Filho WL. 2002. Teaching sustainability at universities. Frankfurt am Main: Peter Lang.

Fink LD. 2003. A Self-Directed Guide to Designing Courses for Significant Learning. University of Oklahoma. http://finkconsulting. info/wp-content/uploads/2011/07/Fink2005SelfDirectedGuideTo CourseDesign.doc 
Gash H. 2009. Inspiration and intellect: significant learning in musical forms and analysis. In: Gertina J, van Schalkwyk RC, D'Amato, editors. New directions for teaching and learning. 1st ed. Wiley Periodicals, Inc.; p. 35-41.

Gehle KS, Crawford JL, Hatcher MT. 2011. Integrating environmental health into medical education. Am J Prevent Med. 41:S296-S301.

Gomez A, Satchit B, Julie N, Aaron H, Jay L. 2013. Perspective: environment, biodiversity, and the education of the physician of the future. Acad Med. 88:168-172.

Green ElH, Blashki G, Berry HL, Harley D, Horton G, Hall G. 2009. Preparing Australian Medical Students for climate change. Aust Fam Physician. 38:726-729.

Hollan S, McMichael A, Haines A, Skuratovskaya L, Haider M, Bach W, Kahan E, De Gruil F, Bastan T, Silberschmidt S, et al. 1998. Medical coalition for a sustainable global environment. Epidemiol Prevenz. 22:70-71.

Howard J. 2004. Challenges facing the adoption of ecosystem health as a core component in professional curricula. EcoHealth. 1(Suppl 1):S16-S22.

Jones J, Hunter D. 1995. Consensus methods for medical and health services research. BMJ. 311:376-380.

Kern DE, Thomas PA, Howard DM, Bass EB. 1998. Curriculum development for medical education: a six-step approach. Baltimore: John Hopkins Press.

Keskin Y, Ozyaral O, LuleciNE, Kaya E. 2011. Environmental views of students attending school of medicine, Maltepe University and confounding factors. In 11th international multidisciplinary scientific geoconference (SGEM 2011), III:1265-1271.

Maxwell J, Blashki G. 2016. Teaching about climate change in medical education: an opportunity. J Public Health Res. 5:14-20.

McMichael AJ, Lindgren E. 2011. Climate change: present and future risks to health, and necessary responses. J Intern Med. 270:401-413.

Pearson D, Walpole S, Barna S. 2015. Challenges to professionalism: social accountability and global environmental change. Med Teach. 37:825-830.

Prado M. L d, Velho MB, Espíndola DS, Sobrinho SH, Backes VMS. 2012. Arco de Charles Maguerez: Refletindo Estratégias de Metodologia Ativa Na Formação de Profissionais de Saúde. Esc Anna Nery. 16:172-177.

Pruss-Ustun A, Corvalán C. 2006. Preventing disease through healthy environments: towards an estimate of the environmental burden of disease. 1st ed. Vol. 12. Geneva: World Health Organization. http://www. who.int/quantifying_ehimpacts/publications/preventingdisease.pdf.

Rapport DJ, Howard J, Lannigan R, McCauley W. 2003. Linking health and ecology in the medical curriculum. Environ Int 29:353-358.

Rawlins SC, Chen A, Rawlins JM, Chadee DD, Legall G. 2007. A knowledge, attitude and practices study of the issues of climate change/ variability impacts and public health in Trinidad and Tobago, and St Kitts and Nevis. West Indian Med J. 56:115-121.

RCP. 2010. How doctors can close the gap tackling the social determinants of health through culture change. London: RCP.

Sanborn M, Kerr KJ, Sanin LH, Cole DC, Bassil KL, Vakil C, Kaur JS. 2007. Non-cancer health effects of pesticides. Can Family Phys. 53:1712-1720.

Schön DA. 1987. Educating the reflective practitioner. San Francisco: Jossey-Bass.

Shomaker TS, Green EM, Yandow SM. 2013. Perspective: one health: a compelling convergence. Acad Med. 88:49-55.

Su C-C, Chen $\mathrm{C}-\mathrm{H}$, Chen S-H, Ping T-C. 2011. Measures to reduce lighting-related energy use and costs at hospital nursing stations. $\mathrm{Hu} \mathrm{Li}$ Za Zhi J Nurs. 58:39-46.

Survey for Sign up to Workshop. 2016. Barcelona. https://www.survey monkey.com/r/Preview/?sm=v6Th7M8dyMrJWWqE_2FqBFAgXCjnH4 k45P8IQqsUgYz6lepWyfeOGTDgQ4Xt2N3AFhxFDt1m0cwcftpNP0Czg 8fAl63opJALJrqdmNiGsxWws_3D.

Takayanagui AMM. 1993. Trabalhadores de Saúde E Meio Ambiente: Açäo Educativa Do Enfermeiro $\mathrm{Na}$ Conscientizaçäo Para Gerenciamento de Resíduos Sólidos. Universidad de Sao Paulo Escola de Enfermagem de Ribeirao Preto Trabalhadores.

Thompson T, Walpole S, Braithwaite I, Inman A, Barna S, Mortimer F. 2014. Learning objectives for sustainable health care. Lancet. 384:1924-1925.

Tomes C. 2011. Teaching sustainable healthcare to tomorrow's doctors: a mixed method analysis of medical school innovations in England. Cambridge: University of Cambridge.

UN General Assembly. 2015. Resolution adopted by the general assembly: transforming our world: the 2030 agenda for sustainable development. New York: UN General Assembly. http://www.un.org/ga/ search/view_doc.asp?symbol=A/RES/70/1\&Lang $=E$.

Walpole SC, Mortimer F, Inman A, Braithwaite I, Thompson T. 2015. Exploring emerging learning needs: a UK-wide consultation on environmental sustainability learning objectives for medical education. Int J Med Educ. 6:191-200.

Walpole SC, Pearson D, Coad J, Barna S. 2015. What do tomorrow's doctors need to learn about ecosystems? - a BEME systematic review: BEME guide no. 36. Med Teach. 10:1-15.

Watts N, Adger WN, Agnolucci P, Blackstock J, Byass P, Cai W, Chaytor S, Colbourn T, Collins M, Cooper A, et al. 2015. Health and climate change: policy responses to protect public health. Lancet. 386:1861-1914.

Whitmee S, Haines A, Beyrer C, Boltz F, Capon AG, de Souza Dias BF, Ezeh A, Frumkin H, Gong $P$, Head $P$, et al. 2015. Safeguarding human health in the Anthropocene epoch: report of The Rockefeller Foundation-Lancet Commission on planetary health. Lancet. 386:1973-2028.

Wilcox BA. 2004. Integrating ecohealth in the school of medicine. Hawaii Med J. 63:316-317 